\title{
Young People's Views on the Design of Adrenaline Auto-Injectors: A Qualitative Study
}

L Leach $^{1}$, HE Smith ${ }^{1,2^{*}}$, C Brown ${ }^{1}$, M Davies $^{1}$ and CJ Jones ${ }^{1,3}$

${ }^{1}$ Department of Primary Care \& Public Health, Brighton \& Sussex Medical School, Brighton, UK

${ }^{2}$ Lee Kong Chian School of Medicine, Nanyang Technological University, Singapore

${ }^{3}$ Department of Clinical Medicine, Brighton \& Sussex Medical School, Brighton, UK

*Corresponding author: Helen E Smith, Family Medicine and Primary Care, Lee Kong Chian School of Medicine, Novena Campus, 11 Mandalay Road, Singapore, Telephone: 656592 3926; E-mail: h.e.smith@ntu.edu.sg

Received date: January 17, 2018; Accepted date: February 02, 2018; Published date: 09 February, 2018

Copyright: (c) 2018 Leach L, et al. This is an open-access article distributed under the terms of the Creative Commons Attribution License, which permits unrestricted use, distribution, and reproduction in any medium, provided the original author and source are credited.

\begin{abstract}
Background: "Young people's compliance with carriage of adrenaline auto-injectors (AAI) may be as low as $41 \%$, yet we lack research exploring their preferences regarding these devices."
\end{abstract}

Objective: This qualitative study explored young people's ideas about AAI design and features which may facilitate their carriage and use.

Methods: Young people aged 13-18 years prescribed an AAI for severe allergic reaction were invited to participate in in-depth, semi-structured, face-to-face interviews about AAI design. Interviews were recorded, transcribed verbatim and analyzed using thematic content analysis.

Results: From 23 interviews, seven major themes were identified: accessibility and carriage, comprehensibility of instructions, indication of correct administration, safety, speed of administration, visibility and identification and precise drug delivery. Young people made several suggestions for how AAls may be adapted to improve carriage, including reduced size to enable pocket-carriage. Comprehensibility was thought to be enhanced by the use of pictographic instructions and audio-prompts to encourage prompt and accurate administration. Needle guards were seen as beneficial to reduce needle phobia, prevent accidental injury and provide reassurance that the device had been administered. Young people were conflicted between wanting a device which enabled discreet carriage, versus an AAI which was bold and clearly identifiable as a medical device in case of emergency.

Conclusion: This study identified key AAl features important to young people, together with design issues deterring day-to-day carriage of AAls and their emergency, time-pressured usage. We demonstrated considerable scope for AAI design modifications to improve young peoples' perception of devices and facilitate their carriage and use.

Keywords: Young people; Adolescents; Teenagers; Adrenaline autoinjector; Design; Preference

\section{Abbreviations: AAI: Adrenaline Auto-injectors}

\section{Introduction}

Due to the fast onset and potentially fatal nature of anaphylaxis, intramuscular adrenaline is the recommended first-line treatment for anaphylaxis [1-5], and early administration is imperative. Numerous adrenaline auto-injectors (AAIs) have been designed so that the immediate self-administration of adrenaline is possible. The risks of accidental, unintentional exposure to allergens and the speed of onset of anaphylaxis require patients to always carry their AAI.

Young people have the highest risk of severe and fatal anaphylactic reactions, with most fatalities being a result of delayed or nonadministration of adrenaline [6-9]. It has been consistently documented that young people's compliance with the carriage and use of AAIs is poor [10-12]. A recent study estimated that $59 \%$ of young people do not carry their AAIs at all times [13]. Even when carried and available for use, $75 \%-83 \%$ of teenagers or the parents of younger children did not use the AAI when needed [14,15]. Despite an apparent reluctance to carry and use AAIs, there has been little exploration of the young peoples' perspective and their ideas for AAI design. We therefore wished to explore young people's views of AAIs, asking them to describe the characteristics that they most value, and what they would wish to be incorporated in future AAI design, particularly focusing on those that would facilitate carriage and use.

\section{Methods}

A qualitative design was selected to enable in-depth exploration of young people's views of AAIs.

\section{Recruitment}

Participants were recruited from outpatient clinics and from general practices in the South East of England. Participants were eligible for inclusion if they were aged 13-18 years, with a prescription of an AAI 
Citation: Leach L, Smith HE, Brown C, Davies M, Jones CJ (2018) Young People's Views on the Design of Adrenaline Auto-Injectors: A Qualitative Study. J Allergy Ther 9: 271. doi:10.4172/2155-6121.1000271

Page 2 of 6

for food allergy or venom allergy indicating a severity of reaction which warrants medication. Eligible participants and their guardians were sent a letter of invitation and information leaflet (participant and parental). Consent was obtained for participants aged 16 years or over For participants aged 13-15 years assent was obtained together with consent from their parents. Recruitment of participants continued until data saturation was achieved, that is no new information was generated from three consecutive interviews.

\section{Interviews}

Face-to-face interviews, were conducted by one of three researchers ( $\mathrm{LB}, \mathrm{MD}$ or $\mathrm{CB}$ ), all trained in qualitative interview techniques, in a setting of the participants' choosing (their general practice surgery, the local Medical School or Hospital). A semi-structured interview guide facilitated coverage of all aspects of design whilst allowing participants to discuss issues of importance to them. Nine different AAI models (current, discontinued and prototypes including Anapen, Auvi-Q, Emerade EpiPen (previous and next generation models), Jext, Oval (two prototypes) and Twinject) were available to stimulate discussion. Interviews were recorded, transcribed verbatim and anonymised.

\section{Data analysis}

Data were analyzed using Bernard's structured method of thematic content analysis [16]. Transcripts were analyzed independently by three researchers (LL, CB and CJ) to generate potential themes. The preliminary analysis was then discussed with the research team and a framework agreed for analysis.

Ethical approval for the study was obtained by the National Institute for Social Care and Health Research RES Committee, Wrexham, REC reference 12/WA/0061.

\section{Results}

Twenty three interviews of 30-60 min duration were conducted. Participants ranged from 13 to 17 years of age, $74 \%$ were female and $17 \%$ had experience of using their AAI (Table 1). Seven major themes were identified each relating to a design feature; accessibility and carriage, comprehensibility of instructions, indication that device had been correctly administered, safety, speed of administration, visibility and identification and precise drug delivery (Table 2).

\begin{tabular}{|l|l|l|l|l|}
\hline $\begin{array}{l}\text { Gende } \\
\text { r }\end{array}$ & Age & Allergen & Current AAl & $\begin{array}{l}\text { Ever used } \\
\text { AAI }\end{array}$ \\
\hline M & 13 & Peanuts, seeds & EpiPen & No \\
\hline F & 14 & Eggs, nuts, seeds & EpiPen & No \\
\hline F & 15 & Fish, strawberries & EpiPen & Yes \\
\hline F & 14 & Latex & Jext & No \\
\hline F & 13 & Nuts & EpiPen & No \\
\hline F & 14 & Nuts & EpiPen & No \\
\hline F & 13 & Nuts, seeds & EpiPen & No \\
\hline F & 13 & Nuts & Jext & Yes \\
\hline F & 16 & Peanuts, legumes & Jext & No \\
\hline F & 15 & Peanuts & EpiPen & No \\
\hline M & 13 & Unknown & EpiPen & No \\
\hline F & 14 & Nuts & EpiPen & No \\
\hline F & 17 & Nuts, seeds & EpiPen & Yes \\
\hline F & 17 & Peanuts, legumes & Jext & No \\
\hline M & 14 & Nuts & Jext & No \\
\hline M & 14 & Nuts & EpiPen & No \\
\hline M & 14 & Peanuts & Noxt & No \\
\hline F & 14 & Nuts & EpiPen & No \\
\hline F & 14 & Nuts, fish & NopiPen & No \\
\hline F & 15 & Apples, pears, nuts & Next \\
\hline F & 17 & Nuts & kiwi, latex & Nhellfish, seeds, \\
\hline M & 16 & Legumes & Next \\
\hline
\end{tabular}

Table 1: Demographics

\begin{tabular}{|l|l|}
\hline Carriage and accessibility & $\begin{array}{l}\text { Reduced size to enable easier carriage } \\
\text { Facility to attach AAI to bag or self }\end{array}$ \\
\hline Comprehensibility of instructions & $\begin{array}{l}\text { Added value of pictures } \\
\text { Needed as a reminder of how to administer } \\
\text { Clear, simple instructions to enable self and bystander use } \\
\text { Benefit of colour coding } \\
\text { Reduced quantity of text } \\
\text { Clear labelling of ends of device } \\
\text { Requirement for instructions to be printed on device } \\
\text { Requirement for text and pictorial instructions }\end{array}$ \\
\hline Indication of correct administration & $\begin{array}{l}\text { Audio confirmation } \\
\text { Needle guard as visual confirmation } \\
\text { Window to show medication has been used }\end{array}$ \\
\hline
\end{tabular}




\begin{tabular}{|l|l|}
\hline Safety features & $\begin{array}{l}\text { Protective casing } \\
\text { Appeal of needle guard/safety cap }\end{array}$ \\
\hline Speed of administration & $\begin{array}{l}\text { Simplicity of device (i.e. number of caps/steps) } \\
\text { Reduced intramuscular needle time }\end{array}$ \\
\hline Visibility and identification & $\begin{array}{l}\text { Bright colours to ensure visibility } \\
\text { Device to resemble medication and be familiar } \\
\text { Device to be discreet and not wishing to stand out from the crowd }\end{array}$ \\
\hline Precise drug delivery & $\begin{array}{l}\text { Ergonomic considerations (i.e. grip) } \\
\text { Injecting mechanism }\end{array}$ \\
\hline Additional features & Multiple doses in once device \\
\hline
\end{tabular}

Table 2: Major themes and subthemes identified

\section{Accessibility and carriage}

All participants discussed the need to modify the size of AAIs to make carriage easier. The majority of participants wanted the device to be smaller to enable pocket carriage, often citing the longer length devices as impractical: "Pocket size-so smaller. Thinner so it doesn't take up so much room. And just easier and more mobile" (Male aged 13). "If you've got it in your pocket then you can just take it out and use it. So it's quite easier if you're having an allergic reaction" (Male aged 13).

Discussion of reduced size was often linked with improved adherence: "Sometimes I leave the house knowing I don't have it (AAI). I think "oh am just popping here and I will be fine." But it is because it is big, like if it was small I would just always have it in my pocket. Like my key-I always have it in my pocket. So if it was smaller I think it would just be a normal thing to have it on me" (Female aged 16). "I would carry it more if it fit it in my pocket" (Male aged 16).

However, a smaller device was recognized to be not without its own problems, particularly that if too small it might get lost. Participants suggested two possible design features to rectify this:

A choice of sizes for different occasions: "It would probably be a good idea to offer people small ones and larger ones, so that they could take them to different places and they have that flexibility" (Female aged 17).

Integrating into the AAI design a mechanism to secure the device to self, clothes or bag: "You could sort of clip it to your bag, so it doesn't fall right to the bottom. And then, when you need it you can find it, so I would say that is helpful" (Female aged 13).

The comments about improving portability were moderated by concern that any significant change in design or dimensions may reduce bystanders' recognition of the device. The participant quoted above went on to say "a lot of people aren't really familiar with it (an AAI) and also, if you are changing the shape or size of it slightly then people will be even less familiar".

\section{Comprehensibility of instructions}

Clear and simple instructions were required at two levels, for young person themselves and for a bystander assisting in an emergency. Young people placed great value on having pictographic instructions which were seen to aid speed of familiarization, but also made the instructions universally accessible, as they were independent of reading ability or linguistic skills:

"Because if people can't read then pictures tell you what to do" (Female aged 15).

"I think pictures are sometimes better for something like this... Because if you don't really have ... again if you don't have time to... to read through all of it" (Female aged 17).

They expressed a strong preference for integration of instructions on the device, "Printed (instructions) on the side of the pen so that you know where it is" (Female aged 13).

One of the devices available to participants to prompt discussion included an audio prompt AAI (Auvi-Q ${ }^{\circ}$ ). The audio-prompt was perceived as a favorable design feature, not just because "not everyone will understand the writing" (Female aged 14), but because listening requires less concentration "It is much easier than reading it. Especially if I am injecting myself I might (be) so panicked that I can't really read instructions" (Female aged 13).

To maximize benefit from an audio-prompt, young people wanted a voice that was 'human', 'normal': "I think it just needs to be more relaxed and flowy. It would obviously relax you a bit and make you calmer rather than a scary formal voice" (Female aged 15).

The utility of the audio-prompt was felt to be greater for new or inexperienced AAI users, competent and confident users expressing minimal utility for them: "Well the speaking thing is good. Well 'needable' for someone who doesn't know what they are doing, whereas usually, and most probably, it will be me using it. So I will know what I am doing anyway" (Female aged 17).

\section{Indication of correct administration}

Young people desired confirmation and reassurance that the device had been administrated correctly and the adrenaline had been delivered.

"I think it is good that there is a click (audible click on some devices) because you know exactly it is done" (Female aged 14).

"This might sound a bit complicated but maybe if it (AAI) just made a noise, in a way, just maybe even if it had a voice recording on it, just to tell you whether it was in. Or if a light came on, or just like this little click" (Male aged 14). 
Some young people considered the emergence of the needle guard on some AAIs after triggering the device acted as visual confirmation of adrenaline delivery: "The orange bit (needle guard) comes out, and the orange bit extends even more so you know when it's like used" (Female aged 14)

\section{Safety features}

Some concerns were raised over the safety and robustness of the external casing of existing devices, as users recalled instances of disintegration and potential accidents, for example: "It is in a tube and the lids are easy to snap off those, and then it (AAI) falls out and then there is like, a chance of it coming out and stabbing you" (Male aged 13).

The inclusion of a needle guard was recognized as feature to reduce accidental injury, particularly to bystanders unfamiliar with the device: "For the safety around it because if you are out and it happens you are usually have other people around you and you just don't want anyone to pick it up" (Female aged 14).

The needle guard was also seen to provide psychological safety, minimizing the impact of needle phobia: "I think the needle guard is really clever because I guess the needle is quite frightening for me. I am not a fan of injections or stuff, so I think that is a clever thing that you can't see it, because maybe it would panic you more about using it next time" (Female aged 14).

\section{Speed of administration}

A simple device, with minimal number of steps between decision to use and delivery was favored by many. Preferences for pull-off caps were expressed as these were considered quicker than screw caps and could therefore reduce the time to injection. "I prefer the one where you just pop off the lid, in a way, rather than having to spend time screwing" (Male aged 14).

However, others were reluctant to sacrifice safety for speed, expressing preference for screw mechanisms: "Screw cap would be best, no risk of it coming off, and as long as it's not one that has to be screwed around loads, then it won't really slow us down" (Female aged 16).

Young people recognized the advantages of an AAI looking like a medical device and labeled appropriately: "If you could write the word adrenaline or something in big letters. Because people would recognize that. People who don't know anything about it would still recognize "Ok, so that is the thing they need"'” (Female aged 17).

\section{Visibility and identification}

Aesthetics were discussed in respect to the AAI being visible and distinct as a medical device. Many participants talked about their preference for a brightly colored device, as one that would be easier to locate, for example in a large bag, and may alert others that the AAI is a medical device to be used in an emergency: "I want to make it quite bright so easy, easy to find wherever you are, but I don't think there's a particular color that would be good for me" (Female aged 14).

"You have got to have it in emergency colors to make it clear that it is something for an emergency" (Female aged 17).

The expressed need for visibility was often accompanied by a desire for the AAI to be "discreet" (Female aged 13).
Young females, having discussed brightly colored devices, often then went on to discuss a need for an AAI to be discreet, enabling them to 'blend in' with the crowd or not to appear obviously untrusting of their hosts' ability to provide an allergen free meal: "It looks like a pen. So people wouldn't ask as many questions. So it would be disguised wouldn't it, so it would be just like in your bag and people wouldn't really question it" (Female aged 15).

"It is good for it to have bright colors so that it stands out, in case I was in a public place and somebody needed to find it, or if my friends needed to find it. But then again it's not the nicest thing to have a bright yellow object just sitting in your bag." (Female aged 17)

"It seems a bit, if you are going around to a friend's house; it is a bit untrusting if you have got it there. If they just see that I have got an EpiPen in my bag, it doesn't seem very polite almost." (Female aged 14)

\section{Precise drug delivery}

The availability of several AAI devices for participants to examine prompted some discussion about the two types of injecting mechanisms used; the "swing and push" and the "hold and press" technique. Participants favored placing the injector on the skin and then pressing; this was perceived to have greater accuracy for the positioning of the injection, as well as causing less pain and not being such a disconcerting action: "I think it's good that you just press in instead of um swinging it because I think swinging it, it could go more wrong, or you could do it too hard, or something. So I think it is clever because you just press it down and I think that is easier as well" (Female aged 14).

"The thought of having to swing something and stab it into you is quite scary. So just having to press something is much better and less frightful" (Female aged 13).

"I think a lot of people are worried about the big swing, like that would hurt, whereas if you jab it in, you don't have to use loads of force" (Female aged 14).

Some suggested the ability to deliver the injection to the appropriate part of the thigh was more likely if changes were made to the shape and grip of the device: "A round shape is easier to hold than a flat one" (Male aged 16).

"Maybe it could have a bit more grip because in case you don't want it to slide out of your fingers when you are doing it, because you are quite nervous and everything. So you don't want to cut yourself or something with it" (Female aged 14).

\section{Additional design features}

Some participants talked about the desirability for a device that was able to deliver multiple doses should an error be made whilst administering the first dose or where access to emergency services was delayed. "I think that would be useful because at the moment I have to carry around two of those, which is quite big" (Female aged 14).

"If the ambulance wasn't, if it didn't come quickly, so you could inject you again" (Female aged 15).

Whilst convenience and compactness of a multiple-dose device was desired this was sometimes accompanied by a fear that it might be more complex to use, and if so this could outweigh the advantages: "I think it is a good idea having another one, but I think it would be much easier to just to have two simple (devices)" (Male aged 14). 
Page 5 of 6

\section{Discussion}

Young people articulated readily their ideas about existing and potential AAI devices, each talking for at least 30 minutes. The seven major themes covered AAI carriage through to utilization and disposal. In particular, there was a desire for design features to improve portability and safety. When reflecting on design features, these young people were alert to both their needs and the needs of others helping them in an emergency. They were attentive to the need for clearer instructions on AAIs generally, instructions that were readily available and accessible to those with reading or linguistic difficulties. The need for such design features are supported by data; in England 16\% of adults are functionally illiterate [17] and the prevalence of unintentional injections of AAIs between 1994 and 2007 reported to the American Association of Poison Control Centers was over 15,000 [18]. The implications of unintentional injection are two fold, the loss of the medication dose needed by the anaphylactic patient and the resulting discomfort and risk for the caregiver or bystander accidentally injected $[19,20]$. These issues were raised more frequently by older participants; perhaps reflecting the greater proportion of time this age group spends away from parents and the increasing need to be dependent on bystanders.

Whilst there was not a consensus on how AAIs should be improved, there were frequent suggestions. This is perhaps most apparent when discussing size of the device and its impact on carriage. There was conflict between the AAI characteristics that facilitate discreet and easy portability on a daily basis, (small AAI with unobtrusive coloring) and the characteristics needed in a rare anaphylactic emergency where prompt administration called for bold coloration and sufficient size to aid easy location. Interestingly young people commented on the disadvantage of changes to AAI design as people were familiar with the somewhat undesirable, existing devices. The importance of device familiarity is probably over-rated given that study after study has demonstrated that patients', careers' and health professionals' are unfamiliar with the administration of even the most commonly prescribed AAIs [21]. There is very little evidence to suggest that the threatened loss of 'familiarity' with existing devices should ever be used as an excuse to impede the development of better AAIs.

The desire to make their AAI less noticeable reflects the stigma of being allergic and the need to fit in as a young person. Many young people are teased about their allergies; this was found to be as high as $62 \%$ in a study of 174 American young people and young adults [10] and $15 \%$ of children in the UK prescribed an AAI reported being bullied [22]. There is an inherent tension in young people's desires to carry a device which is discreet and inconspicuous and yet immediately identifiable in an emergency situation. Whether this tension could be entirely resolved is doubtful but it is important to consider how users' anxieties relating to peer stigma and aesthetics can be balanced with the need for the prompt identification of AAIs in an emergency setting.

This research complements a previous study which focused only on robustness and performance qualities of AAIs [23]. Our research adds to an existing review of design focusing only on the pharmacokinetics and ballistics of AAIs from a professional perspective [24]. Interestingly there are similarities between prescribers and users with respect to pharmacological and clinical matters; the need for a device which is simple and quick to administer in high stress situations, is easy to carry and access, one that involves minimal steps to administration and is safe were reported by professionals and also by the young people in our study $[24,25]$. Human factors engineering, the design of systems which conform to human capabilities and limitations [26], has suggested that current AAIs are poorly designed, with some models based on a metaphor (a pen), but not operated consistently with that metaphor, leading to confusion during administration [27]. Involving users in the design phase of medicinal products is crucial; research has demonstrated that testing a product on as few as four or five users enables manufacturers to discover $80 \%$ of a product's usability problems [28].

This is a novel study exploring young persons' experience of the carriage and use of AAIs, the qualitative approach allowed for in-depth understanding of perceptions and opinions that would be difficult to capture in a survey or questionnaire. Our participants were recruited from a single geographical area; however the issues raised are likely to be generalizable to all AAI users, as they relate to matters independent of the health care system. We recruited young people with varying degrees of experience of AAI administration, and different prescriptions of AAIs. One may argue that as many participants had not previously used an AAI, they are unable to comment on design when in fact we would argue that an unappealing design affects adherence to carriage and impedes use which has been observed in adults with allergy [29]. We did not record data on ethnicity but as the geographical region is largely Caucasian, future work needs to explore whether there are different cultural requirements. Our research method was rigorous and analysis transparent, enabling the reader to assess the transferability of our respondent comments to their locality. After 23 respondents we had reached data saturation, whilst this is a small sample size for quantitative studies, it is sufficient for qualitative research where there was dense specificity, a narrow aim and strong interview quality dialogue, all indicative of high information power [30].

Young people can generate ideas for future AAI design which improve their perceptions of the device and may facilitate their carriage and use. AAI designers need to address these unmet requirements with experience-based designs if we are to achieve optimal self-management of severe allergy and anaphylaxis.

\section{References}

1. Muraro A, Roberts G, Worm M, Bilò MB, Brockow K, et al. (2014) Anaphylaxis: guidelines from the European Academy of Allergy and Clinical Immunology. Allergy 69: 1026-1045.

2. Simons FER, Ebisawa M, Sanchez-Borges M, Thong BY, Worm M, et al. (2015) 2015 update of the evidence base: World Allergy Organization anaphylaxis guidelines. World Allergy Organ J 8: 32.

3. Muraro A, Roberts G, Clark A, Eigenmann PA, Halken S, et al. (2007) The management of anaphylaxis in childhood: position paper of the European academy of allergology and clinical immunology. Allergy Aug 62: 857-871.

4. Soar J, Pumphrey R, Cant A, Clarke S, Corbett A, et al. (2008) Emergency treatment of anaphylactic reactions--guidelines for healthcare providers. Resuscitation 77: 157-169.

5. Posner L, Carmago CA (2017) Update on the usage and safety of epinephrine auto-injectors, 2017. Drug Healthc Patient Saf 9: 9-18.

6. Bock SA, Munoz-Furlong A, Sampson HA (2001) Fatalities due to anaphylactic reactions to foods. J Allergy Clin Immunol 107: 191-193.

7. Pumphrey RS (2000) Lessons for management of anaphylaxis from a study of fatal reactions. Clin Exp Allergy 30: 1144-1150.

8. Bock SA, Munoz-Furlong A, Sampson HA (2007) Further fatalities caused by anaphylactic reactions to food, 2001-2006. J Allergy Clin Immunol 119: 1016-1018. 
Citation: Leach L, Smith HE, Brown C, Davies M, Jones CJ (2018) Young People's Views on the Design of Adrenaline Auto-Injectors: A Qualitative Study. J Allergy Ther 9: 271. doi:10.4172/2155-6121.1000271

Page 6 of 6

9. Pumphrey RS, Gowland MH (2007) Further fatal allergic reactions to food in the United Kingdom, 1999-2006. J Allergy Clin Immunol 119: 1018-1019.

10. Sampson MA, Munoz-Furlong A, Sicherer SH (2006) Risk-taking and coping strategies of adolescents and young adults with food allergy. J Allergy Clin Immunol 117: 1440-1445.

11. Greenhawt MJ, Singer AM, Baptist AP (2009) Food allergy and food allergy attitudes among college students. J Allergy Clin Immunol 124 323-327.

12. Gallagher M, Worth A, Cunningham-Burley S, Sheikh A (2012) Strategies for living with the risk of anaphylaxis in adolescence: qualitative study of young people and their parents. Prim Care Respir J 21: 392-397.

13. Jones CJ, Llewellyn CD, Frew AJ, Du Toit G, Mukhopadhyay S, et al. (2015) Factors associated with good adherence to self-care behaviours amongst adolescents with food allergy. Pediatr Allergy Immunol 26: 111-118.

14. Saleh-Langenberg J, Flokstra-de Blok BM, Goossens NJ, Kemna JC, van der Velde JL, et al. (2016) The compliance and burden of treatment with the epinephrine auto-injector in food-allergic adolescents. Pediatr Allergy Immunol 27: 28-34

15. Noimark L, Wales J, Du Toit G, Pastacaldi C, Haddad D, et al. (2012) The use of adrenaline auto injectors by children and teenagers. Clin Exp Allergy 42: 284-292.

16. Burnard P (1991) A method of analysing interview transcripts in qualitative research. Nurse Educ Today 11: 461-466.

17. http://www.literacytrust.org.uk/adult_literacy/ illiterate_adults_in_england

18. Simons FE, Edwards ES, Read EJ Jr, Clark S, Liebelt EL (2010) Voluntarily reported unintentional injections from epinephrine auto-injectors. J Allergy Clin Immunol 125: 419-423.

19. Simons FE, Lieberman PL, Read EJ, Jr. Edwards ES (2009) Hazards of unintentional injection of epinephrine from autoinjectors: a systematic review. Ann Allergy Asthma Immunol 102: 282-287.
20. Simons KJ, Simons FE (2010) Epinephrine and its use in anaphylaxis: current issues. Curr Opin Allergy Clin Immunol 10: 354-361.

21. El-Turki A, Smith H, Lllewellyn C, Jones CJ (2017) A systematic review of patients', parents' and healthcare professionals' adrenaline auto-injector administration techniques. Emerg Med J 34: 403-416.

22. Singh J, Aszkenasy OM (2003) Prescription of adrenaline auto-injectors for potential anaphylaxis- a population survey. Public Health 117: 256-259.

23. Schwirtz A, Seeger H (2012) Comparison of the robustness and functionality of three adrenaline auto-injectors. J Asthma Allergy 5: 39-49.

24. Frew AJ (2011) What are the 'ideal' features of an adrenaline (epinephrine) auto-injector in the treatment of anaphylaxis? Allergy 66: 15-24.

25. Greenberger PA, Wallace DV, Lieberman PL, Gregory SM (2017) Contemporary issues in anaphylaxis and the evolution of epinephrine autoinjectors: What will the future bring? Ann Allergy Asthma Immunol 119: 333-338.

26. Welch D (1998) Human factors in the health care facility. Biomed Instrum Technol 32: 311-316.

27. Gosbee LL (2004) Nuts! I can't figure out how to use my life-saving epinephrine auto-injector! Jt Comm J Qual Saf 30: 220-223.

28. Virzi RA (1992) Refining the test phase of usability evaluation: How many subjects Is enough? Human Factors 34: 457-486.

29. Money AG, Barnett J, Kuljis J, Lucas J (2013) Patient perceptions of epinephrine auto-injectors: exploring barriers to use. Scand J Caring Sci 27: 335-344.

30. Malterud K, Siersma VD, Guassora AD (2016) Sample size in qualitative studies; guided by information power. Qual Health Res 26: 1753-1760. 